\title{
Impact of eplerenone on major cardiovascular outcomes in patients with systolic heart failure according to baseline heart rate
}

(Short title: Eplerenone and heart rate)

Ken Lee Chin ${ }^{1}$, Timothy Collier ${ }^{2}$, Stuart Pocock ${ }^{2}$, Bertram Pitt ${ }^{3}$, John J.V. McMurray ${ }^{4}$, Dirk J. van Veldhuisen ${ }^{5}$, Karl Swedberg ${ }^{6,7}$, John Vincent ${ }^{8}$, Faiez Zannad ${ }^{9}$, Danny Liew ${ }^{1}$

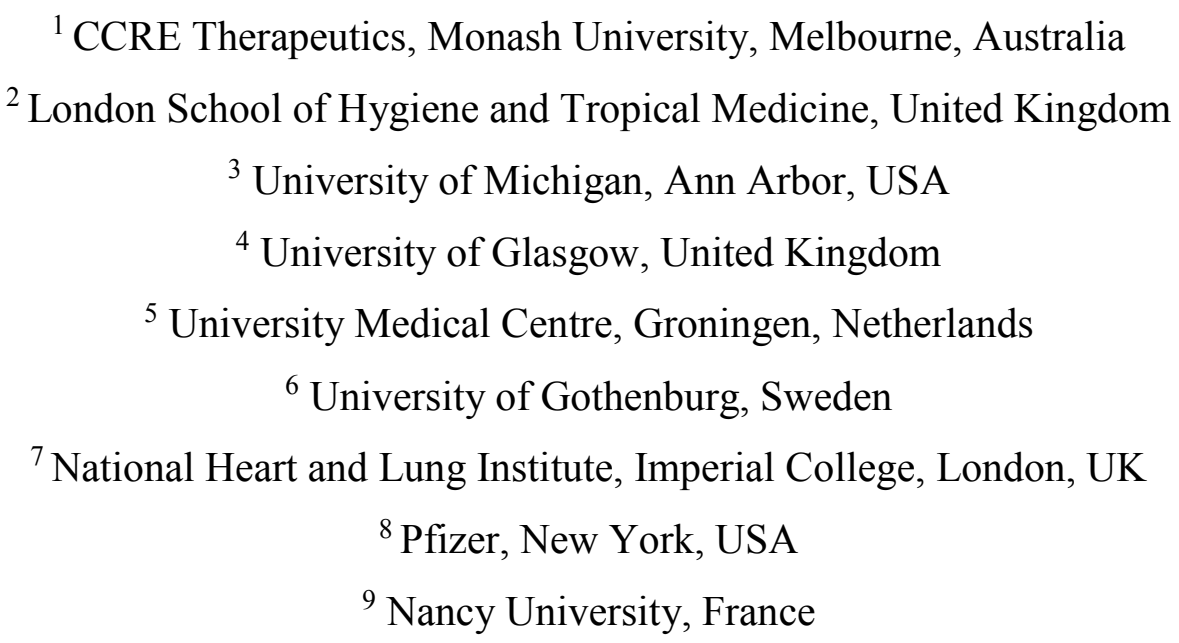

In memory of Henry Krum

Corresponding Author:

Dr Ken Chin

Centre of Cardiovascular Research \& Education (CCRE) in Therapeutics

Department of Epidemiology \& Preventive Medicine

Monash University/Alfred Hospital

553 St Kilda Rd

Melbourne Vic 3004 Australia

Tel: +61 399030342

Fax: +61 399030556

Email: ken.chin@monash.edu 


\section{Abstract}

\section{Background}

Increased resting heart rate is a risk factor for cardiovascular mortality and morbidity. Mineralocorticoid receptor antagonists (MRAs) have been shown to improve cardiac sympathetic nerve activity, reduce heart rate and attenuate left ventricular remodelling. Whether or not the beneficial effects of MRA are affected by heart rate in heart failure patients with reduced ejection fraction (HFREF) is unclear.

\section{Methods}

We undertook a secondary analysis of data from the Eplerenone in Mild Patients Hospitalization and Survival Study in Heart Failure (EMPHASIS-HF) study to assess if clinical outcomes, as well as the efficacy of eplerenone, varied according to heart rate at baseline.

\section{Results}

High resting heart rate of $80 \mathrm{bpm}$ and above predisposed patients to greater risk of all outcomes in the trial, regardless of treatment allocation. The beneficial effects of eplerenone were observed across all categories of heart rate. Eplerenone reduced the risk of primary endpoint, the composite of cardiovascular death and hospitalisation for heart failure, by $30 \%$ (aHR, 0.70; 95\% CI, 0.54 to 0.91 ) in subjects with heart rate $\geq 80 \mathrm{bpm}$, and by $48 \%$ (aHR, $0.52 ; 95 \% \mathrm{CI}, 0.33$ to 0.81$)$ in subjects with heart rate $\leq 60 \mathrm{bpm}$. Eplerenone also reduced the risks of hospitalisation for heart failure, cardiovascular deaths and all-cause deaths independently of baseline heart rate. 
Page 3 of 24

\section{Conclusions}

Baseline heart rate appears to be an important predictor of major clinical outcome events in patients with HFREF, as has been previously reported. The benefits of eplerenone were preserved across all categories of baseline heart rate, without observed heterogeneity in the responses.

Key words: ClinicalTrials.gov identifier: NCT00232180; heart rate; aldosterone antagonists; aldosterone; heart failure 


\section{Introduction}

Elevated resting heart rate is an established risk factor for cardiovascular mortality and morbidity in people with cardiovascular disease [1]. The magnitude of autonomic dysfunction is partly reflected by heart rate [2], and increased heart rate accelerates the progression of coronary atherosclerosis, as well as predisposes to myocardial ischaemia, ventricular arrhythmias and left ventricular dysfunction $[3,4]$.

Lower resting heart rate was associated with better prognosis for patients with heart failure with reduced ejection fraction (HFREF) in sinus rhythm, regardless of beta-blocker (BB) use in the Candesartan in Heart Failure: Assessment of Reduction in Mortality and morbidity (CHARM) program [5]. In a meta-analysis of randomised controlled trials comparing $\mathrm{BB}$ and placebo in patients with HFREF [6], higher heart rate was associated with a higher risk of all-cause mortality for patients in sinus rhythm [adjusted hazards ratio (aHR), 1.11 per 10 beats per min (bpm); 95\% confidence interval (CI), 1.07 to 1.15 ], but not atrial fibrillation (AF) (aHR, 1.03 per $10 \mathrm{bpm}$; 95\% CI, 0.97 to 1.08). Furthermore, patients with the highest heart rates at baseline had the greatest reduction in outcomes after being treated with ivabradine in the Systolic Heart failure treatment with the If inhibitor ivabradine Trial (SHIFT) [7].

Aldosterone is known to augment the sympathetic activity of catecholamines by attenuating their uptake by myocardial tissues, leading to autonomic dysfunction [8]. It also blunts the baroreceptor response by decreasing parasympathetic action via stimulation of $\mathrm{Na}^{+} / \mathrm{K}^{+} / \mathrm{ATPase}$ [9]. It is for these reasons that the mineralocorticoid receptor antagonists (MRAs) improve cardiac autonomic function, reduce heart rate and attenuate left ventricular remodelling [10-12]. While the clinical benefits of MRAs are mainly driven by mineralocorticoid receptor antagonism, it is not known whether these effects vary according to heart rate. This is a relevant question in view of the interaction of MRAs with the 
sympathetic nervous system and because heart rate reflects sympathetic activity. Accordingly, we sought to determine the efficacy of the MRA eplerenone according to baseline heart rate in the Eplerenone in Mild Patients Hospitalization and Survival Study in Heart Failure (EMPHASIS-HF) study.

\section{Methods}

Study design and patient population

The patients involved in EMPHASIS-HF have been described in detail previously [13,14]. In brief, patients were eligible for enrolment if they: i) had New York Heart Association (NYHA) class II symptoms; ii) were $>55$ years of age; iii) had an ejection fraction of no more than $30 \%$ (or $30 \%-35 \%$ if QRS duration $>130 \mathrm{~ms}$ ); iv) were receiving standard background heart failure therapy comprising angiotensin-converting enzyme (ACE) inhibitors, angiotensin receptor blockers (ARB) (or both), and $\mathrm{BB}$ at recommended or maximal tolerated doses; and v) had been hospitalised for cardiovascular reasons within the past six months, or had a plasma B-type natriuretic peptide (BNP) of at least $250 \mathrm{pg} / \mathrm{mL}$ or N terminal proBNP (NT-proBNP) $\geq 500 \mathrm{pg} / \mathrm{mL}$ for males and $\geq 750 \mathrm{pg} / \mathrm{mL}$ for females within 15 days prior to randomisation. Investigators were encouraged to up-titrate patients to the highest stable doses of these therapies before randomisation. Key exclusion criteria included an indication for MRA treatment according to current heart failure guidelines, need for adjunctive potassium-sparing diuretic therapy, serum potassium $>5.0 \mathrm{mmol} / \mathrm{L}$ within 24 hours prior to randomisation, estimated glomerular filtration rate $<30 \mathrm{~mL} / \mathrm{min} / 1.73 \mathrm{~m}^{2}$ within 24 hours prior to randomisation, and any other significant co-morbid condition.

Patients were randomised to receive either eplerenone (up to $50 \mathrm{mg}$ daily) or placebo, in addition to recommended therapy. Patients were reviewed four weeks after randomisation and then every four months during follow-up. The primary outcome was the composite of 
death from cardiovascular causes or hospitalisation for heart failure. An independent Endpoint Events Committee adjudicated all the study endpoint events. The trial was stopped prematurely due to evidence of overwhelming benefit with eplerenone, after a median followup period of 21 months.

In the present analysis, we undertook a post hoc assessment of clinical outcomes according to heart rate at baseline, as well as of the efficacy of eplerenone according to baseline heart rate categories. Event rates for the primary composite outcome and its components were calculated according to study treatment assignment (eplerenone or placebo) and baseline heart rate was categorised a priori into the groups $<60,60-69,70-79$ and $80+$ bpm. The cut-points for these groups corresponded closely to those for quartiles of the heart rate distribution in the sample $(62,71,82 \mathrm{bpm})$. The consequent event rates and $95 \% \mathrm{CI}$ were based on the Poisson distribution, adjusted for age, sex, race, systolic blood pressure, body mass index, left ventricular ejection fraction, serum creatinine, cause of heart failure, duration of heart failure, diabetes mellitus, AF, hypertension, prior hospitalisation for heart failure, stroke, implantable cardioverter-defibrillator/cardiac-resynchronisation therapy and medications (ACE inhibitors/ARBs, BBs, BBs dose, non-dihydropyridine calcium channel blockers, digoxin and antiarrhythmic agents). Efficacy analyses were performed using a multivariable Cox proportional hazards models, adjusted for the same list of covariates stated above. All p-values were two sided. Analyses were performed using Stata Version 15 (StataCorp 2015).

\section{Results}

Baseline characteristics according to heart rate

Of the total of 2,737 patients in the EMPHASIS-HF, data from 2,736 patients were available for the analysis. Baseline characteristics of patients according to heart rate are 
summarised in Table 1. At baseline, a total of $844(31 \%)$ had history of AF. Patients with higher baseline heart rate were younger, and more likely to have elevated diastolic blood pressure, non-ischaemic aetiology of heart failure, AF or flutter, diabetes, prior hospitalisation for heart failure, and be prescribed diuretics and digoxin. In contrast, patients with lower heart rate were more likely to be ex-smokers, have an ischaemic origin of heart failure, coronary artery disease, a history of undergoing percutaneous coronary interventions and coronary artery bypass grafting, implantable cardiac defibrillator, and be prescribed BB, non-dihydropyridine calcium channel blockers, antiarrhythmic agents, antithrombotics and lipid lowering drugs. More than $80 \%$ of the patients were prescribed ACE inhibitors/ARB and BB.

Association between baseline heart rate and clinical outcomes

Results pertaining to the primary endpoint (composite of cardiovascular death or hospitalisation for heart failure), cardiovascular death alone, hospitalisation for heart failure alone and all-cause mortality according to baseline resting heart rate are summarised in Table 2 and Figure 1. Compared to patients with a baseline heart rate of $60-69 \mathrm{bpm}$, those with baseline heart rate of $80+\mathrm{bpm}$ experienced a greater rate of the primary endpoint (17.2 per 100 patient-year versus 10.5 per 100 patient-year, adjusted hazard ratio (aHR) $1.61,95 \%$ CI 1.31 to 1.99$)$. The rates of cardiovascular death, hospitalisation for heart failure and all-cause mortality were also significantly higher.

Figure 2 depicts adjusted event rates for each outcome according to baseline heart rate categories and randomised group. Lower event rates were observed in eplerenone compared with placebo in each heart rate category, with similar absolute differences in event rates across the categories. 
The beneficial effects of eplerenone were preserved across all heart rate categories (Figure 3). The reduction in the primary endpoint and hospitalisation for heart failure were consistently above $30 \%$ across all heart rates, favouring eplerenone (Figure 3). Eplerenone reduced the risk of primary endpoint by $30 \%$ (aHR, $0.70 ; 95 \% \mathrm{CI}, 0.54$ to 0.91 ) among patients with baseline heart rate $\geq 80 \mathrm{bpm}$ and by $48 \%$ (aHR, $0.52 ; 95 \% \mathrm{CI}, 0.33$ to 0.81 ) among patients with baseline heart rate $\leq 60 \mathrm{bpm}$. Similar results were observed in hospitalisation for heart failure. Eplerenone also reduced the risks of cardiovascular and allcause deaths risks in a similar fashion, but with broad confidence interval bands that crossed the null value in subgroups with heart rate $70 \mathrm{bpm}$ and above. However, there was no evidence of interaction between eplerenone and heart rate (trend $P$-value $=0.08$ to 0.73 ). Also, AF was not found to modify the effect of eplerenone (trend $P$-value $=0.59$ ).

A total of $61(2 \%)$ patients were excluded from the fully adjusted models due to missing data on risk factors. Subsequent sensitivity analyses using multiple imputation with chained equations did not change the conclusions. Further exploratory analysis treating heart rate as a continuous variable was carried out but did not add to or alter any conclusions.

\section{Discussion}

To the best of our knowledge, this is the first study to examine the influence of heart rate on subsequent cardiovascular events in a trial using a MRA in patients with heart failure. We found that a high resting heart rate of $80+\mathrm{bpm}$ predisposed patients with HFREF to a greater risk of primary endpoint, cardiovascular deaths, hospitalisation for heart failure and all-cause death, regardless of treatment allocation. The beneficial effects of eplerenone were preserved across all categories of baseline heart rate.

Notably, patients with higher baseline heart rates displayed distinct clinical characteristics compared to those with lower heart rates, with a trend towards lower use of 
BBs and higher prevalence of AF or flutter, diabetes and previous hospitalisation for heart failure. Such discrepancies may explain the increased heart rate and possible decrease in the effect of eplerenone on mortality.

Higher heart rate may reflect a compensatory mechanism for the loss of atrial contribution to cardiac output $[15,16]$. Autonomic dysfunction in heart failure, characterised by decreased tonic and reflex vagal heart rate modulation and increased heart rate, venous plasma norepinephrine and cardiac norepinephrine stores, has been associated with greater mortality [17]. Higher heart rate is also associated with increased energy expenditure, reduced myocardial oxygen delivery because of shorter diastole, and loss of the positive force-frequency relationship (Bowditch effect).[18] Over-activity of the sympathetic nervous system in heart failure, which is reflected by heart rate, has direct toxic effects on the cardiac myocytes, facilitates the development of ventricular arrhythmias and alteration of the betaadrenoceptor function [19].

Accumulated evidence from the SHIFT, CHARM, and Efficacy of Vasopressin Antagonism in Heart Failure: Outcome Study with Tolvaptan (EVEREST) trials support heart rate being an independent predictor of mortality and cardiovascular outcomes, and also highlight the importance of a heart rate reduction strategy for improvement of clinical outcomes in patients with HFREF [5,20,21]. A resting heart rate of $>76 \mathrm{bpm}$ at any time during follow-up was associated with increased risk of cardiovascular death or hospitalisation for HF in the SHIFT and CHARM studies [7,22]. However, these findings do not apply to all patients with HFREF, as some studies have showed paradoxical findings of lower heart rate being associated with higher mortality in heart failure patients with concomitant $\mathrm{AF}$, and to date, the mechanistic explanation for this interaction is less well established [5,23,24]. Although ivabradine does not reduce heart rate and BBs do not improve outcomes in patients 
with HFREF and AF, treatment with MRAs has been demonstrated to reduce both heart rate and major cardiovascular outcomes in this subgroup of patients [12,25].

Despite this, recent data from prospective observational studies suggest that MRAs remained under-prescribed and frequently discontinued among eligible patients with HFREF.[26-28] Only $40 \%$ to $60 \%$ of the patients in the BIOlogy Study to TAilored Treatment in Chronic Heart Failure (BIOSTAT-CHF) and Swedish Heart Failure Registry were prescribed a MRA [26,28]. In these studies, higher heart rate, lower use of BBs, history of diabetes, AF, hypertension, stroke/transient ischaemic attack, smoking, previous percutaneous coronary revascularisation, anaemia and the use of loop diuretics were associated with non-prescribing and under-dosing of MRAs among patients with HFREF. The observed association between heart rate and use of MRAs in these studies is likely to be confounded.

The use of MRAs in HFREF has been shown to be cost-effective and has a significant impact on mortality and hospitalisation rates [29-32]. What is clear from our analysis is that the beneficial effects of eplerenone are preserved regardless of heart rate and higher heart rate is detrimental to patients with HFREF. These findings highlight the importance of optimising use of MRAs in eligible patients with HFREF.

\section{Limitations}

There are a number of limitations to our post hoc analysis. First, analysis was confined to that of heart rate at baseline only; post-randomisation heart rates were not measured. In addition, we relied on investigator-reported baseline heart rate, which may not have been measured in a standardised manner, and estimation of the ventricular rate in patients with AF may also have been less reliable than in patients in sinus rhythm. However, previous analyses examining the relationship between heart rate and pharmacological 
intervention in HFREF trials were also limited to baseline heart rate measured by investigators.[5,6,33] As with all subgroup analyses, there was less precision in the results for groups defined by baseline heart rate, reflected by wide 95\% CIs. Furthermore, we acknowledge that our post hoc analyses were not pre-specified. Nonetheless, a dose-response effect was clear, the findings are of clinical relevance and they accord with those of other studies.

\section{Conclusions}

Baseline heart rate is a predictor of major clinical outcome events in patients with HFREF, as has been previously reported. The cardiovascular benefits of eplerenone in this patient population are preserved across all ranges of baseline heart rate.

\section{Acknowledgement}

The late Professor Henry Krum made substantial contributions to the study.

\section{Sources of Funding}

The EMPHASIS-HF Study was sponsored by Pfizer.

\section{Conflicts of Interest}

Drs Pitt, McMurray, Swedberg, van Veldhuisen, Pocock, and Zannad were members of the EMPHASIS-HF Writing Committee and report having received fees and travel support in the past from the study sponsor, Pfizer Inc, for participation in and traveling to meetings of the committee. Dr Vincent is currently employed by Pfizer and own stock in Pfizer Inc, the makers of eplerenone. Dr Pitt reports receiving fees for serving on the board of Novartis, consulting fees from Takeda, AstraZeneca, Boehringer Ingelheim, GE Healthcare, Relypsa, 
BG Medicine, Nile Therapeutics, Merck, Forest Laboratories, and Novartis, grant support from Forest Laboratories and Novartis, and stock options from Relypsa, BG Medicine, Nile Therapeutics, and Aurasenc and that his institution receives grant support from Forest Laboratories on his behalf and he and his institution receive grant support from Bayer. Dr Swedberg has received research support from Pfizer, Amgen, Novartis, and Servier. Dr Pocock reports receiving consulting fees from Servier, Amgen, AstraZeneca, and Novartis and that his institution receives grants from Servier and AstraZeneca on his behalf. Dr Zannad reports receiving fees for serving on the board of Boston Scientific, consulting fees from Novartis, Takeda, AstraZeneca, Boehringer Ingelheim, GE Healthcare, Relypsa, Servier, Boston Scientific, Bayer, Johnson \& Johnson, and Resmed, and speaker's fees from Pfizer and AstraZeneca and that his institution receives grant support from BG Medicine and Roche Diagnostics on his behalf. Dr Liew reports receiving grants and honoraria from Abbvie, Amgen, AstraZeneca, Bayer, Boehringer Ingelheim, Bristol Myers Squibb, Novartis, Pfizer, Sanofi and Shire. All other authors have reported that they have no relationships relevant to the contents of this paper to disclose.

\section{References}

1. Custodis F, Reil J-C, Laufs U, Böhm M (2013) Heart rate: A global target for cardiovascular disease and therapy along the cardiovascular disease continuum. J Cardiol 62:183-187

2. Komajda M (2015) Heart rate in chronic heart failure: an overlooked risk factor. Eur Heart J 36:648-649

3. Fox K, Borer JS, Camm AJ, Danchin N, Ferrari R, Sendon JLL, Steg PG, Tardif J-C, Tavazzi L, Tendera M, for the Heart Rate Working Group (2007) Resting heart rate in cardiovascular disease. J Am Coll Cardiol 50:823-830 
4. Custodis F, Schirmer SH, Baumhäkel M, Heusch G, Böhm M, Laufs U (2010) Vascular pathophysiology in response to increased heart rate. J Am Coll Cardiol 56:1973-1983

5. Castagno D, Skali H, Takeuchi M, Swedberg K, Yusuf S, Granger CB, Michelson EL, Pfeffer MA, McMurray JJV, Solomon SD, for the CHARM Investigators (2012) Association of heart rate and outcomes in a broad spectrum of patients with chronic heart failure: Results from the CHARM (Candesartan in Heart Failure: Assessment of Reduction in Mortality and morbidity) Program. J Am Coll Cardiol 59:1785-1795

6. Kotecha D, Flather MD, Altman DG, Holmes J, Rosano G, Wikstrand J, Packer M, Coats AJS, Manzano L, Böhm M, van Veldhuisen DJ, Andersson B, Wedel H, von Lueder TG, Rigby AS, Hjalmarson $\AA$, Kjekshus J, Cleland JGF, on behalf of the Beta-Blockers in Heart Failure Collaborative Group (2017) Heart rate and rhythm and the benefit of betablockers in patients with heart failure. J Am Coll Cardiol 69:2885-2896

7. Böhm M, Swedberg K, Komajda M, Borer JS, Ford I, Dubost-Brama A, Lerebours G, Tavazzi L, on behalf of the SHIFT Investigators (2010) Heart rate as a risk factor in chronic heart failure (SHIFT): the association between heart rate and outcomes in a randomised placebo-controlled trial. Lancet 376:886-894

8. Struthers AD (2002) Aldosterone: Cardiovascular assault. Am Heart J 144:S2-7

9. Davies JI, Witham MD, Struthers AD (2005) Autonomic effects of spironolactone and MR blockers in heart failure. Heart Fail Rev 10:63-69

10. Yee K, Struthers AD (1998) Aldosterone blunts the baroreflex response in man. Clin Sci (Lond) 95:687-692

11. Kasama S, Toyama T, Kumakura H, Takayama Y, Ichikawa S, Suzuki T, Kurabayashi M (2003) Effect of spironolactone on cardiac sympathetic nerve activity and left ventricular remodeling in patients with dilated cardiomyopathy. J Am Coll Cardiol 41:574-581 
12. MacFadyen RJ, Barr CS, Struthers AD (1997) Aldosterone blockade reduces vascular collagen turnover, improves heart rate variability and reduces early morning rise in heart rate in heart failure patients. Cardiovasc Res 35:30-34

13. Zannad F, McMurray JJV, Krum H, van Veldhuisen DJ, Swedberg K, Shi H, Vincent J, Pocock S, Pitt B, for the EMPHASIS-HF Study Group (2011) Eplerenone in patients with systolic heart Failure and mild symptoms. N Engl J Med 364:11-21

14. Zannad F, McMurray JJV, Drexler H, Krum H, van Veldhuisen DJ, Swedberg K, Shi H, Vincent J, Pitt B (2010) Rationale and design of the Eplerenone in Mild Patients Hospitalization And SurvIval Study in Heart Failure (EMPHASIS-HF). Eur J Heart Fail $12: 617-622$

15. Rawles JM (1990) What is meant by a "controlled" ventricular rate in atrial fibrillation? Br Heart J 63:157-161

16. Atwood JE, Myers J, Sullivan M, Forbes S, Friis R, Pewen W, Callaham P, Hall P, Froelicher V (1988) Maximal exercise testing and gas exchange in patients with chronic atrial fibrillation. J Am Coll Cardiol 11:508-513

17. Floras JS, Ponikowski P (2015) The sympathetic/parasympathetic imbalance in heart failure with reduced ejection fraction. Eur Heart J 36:1974-1982

18. Böhm M, Perez A-C, Jhund PS, Reil JC, Komajda M, Zile MR, McKelvie RS, Anand IS, Massie BM, Carson PE, McMurray JJV, on behalf of the I-Preserve Committees and Investigators (2014) Relationship between heart rate and mortality and morbidity in the irbesartan patients with heart failure and preserved systolic function trial (I-Preserve). Eur J Heart Fail 16:778-787

19. Kaye D, Lefkovits J, Jennings GL, Bergin P, Broughton A, Esler MD (1995) Adverse consequences of high sympathetic nervous activity in the failing human heart. J Am Coll Cardiol 26:1257-1263 
20. Greene SJ, Vaduganathan M, Wilcox JE, Harinstein ME, Maggioni AP, Subacius H, Zannad F, Konstam MA, Chioncel O, Yancy CW, Swedberg K, Butler J, Bonow RO, Gheorghiade M, on behalf of the EVEREST Trial Investigators (2013) The prognostic significance of heart rate in patients hospitalized for heart failure with reduced ejection fraction in sinus rhythm: Insights from the EVEREST (Efficacy of Vasopressin Antagonism in Heart Failure: Outcome Study With Tolvaptan) trial. J Am Coll Cardiol HF 1:488-496

21. Swedberg K, Komajda M, Böhm M, Borer JS, Ford I, Dubost-Brama A, Lerebours G, Tavazzi L, on behalf of the SHIFT Investigators (2010) Ivabradine and outcomes in chronic heart failure (SHIFT): a randomised placebo-controlled study. Lancet (376):875885

22. Vazir A, Claggett B, Jhund P, Castagno D, Skali H, Yusuf S, Swedberg K, Granger CB, McMurray JJV, Pfeffer MA, Solomon SD (2015 ) Prognostic importance of temporal changes in resting heart rate in heart failure patients: an analysis of the CHARM program. Eur Heart J 36:669-675

23. Bertomeu-González V, Núñez J, Núñez E, Cordero A, Fácila L, Ruiz-Granell R, Quiles J, Sanchis J, Bodí V, Miñana G, Bertomeu V, Llàcer A (2010) Heart rate in acute heart failure, lower is not always better. Int J Cardiol 145:592-593

24. Rienstra M, Van Gelder IC, Van den Berg MP, Boomsma F, Hillege HL, Van Veldhuisen DJ (2006) A comparison of low versus high heart rate in patients with atrial fibrillation and advanced chronic heart failure: Effects on clinical profile, neurohormones and survival. Int J Cardiol 109:95 - 100

25. Swedberg K, Zannad F, McMurray JJV, Krum H, van Veldhuisen DJ, Shi H, Vincent M, John , Pitt B, for the EMPHASIS-HF Study Investigators (2012) Eplerenone and atrial fibrillation in mild systolic heart failure Results from the EMPHASIS-HF (Eplerenone in 
Mild Patients Hospitalization And SurvIval Study in Heart Failure) Study. J Am Coll Cardiol 59:1598-1603

26. Ferreira JP, Rossignol P, Machu J-L, Sharma A, Girerd N, Anker SD, Cleland JG, Dickstein K, Filippatos G, Hillege HL, Lang CC, ter Maaten JM, Metra M, Ng L, Ponikowski P, Samani NJ, van Veldhuisen DJ, Zwinderman AH, Voors AA, Zannad F (2017) Mineralocorticoid receptor antagonist pattern of use in heart failure with reduced ejection fraction: findings from BIOSTAT-CHF. Eur J Heart Fail 19:1284-1293

27. Komajda M, Anker SD, Cowie MR, Filippatos GS, Mengelle B, Ponikowski P, Tavazzi L, on behalf of the QUALIFY Investigators (2016) Physicians' adherence to guidelinerecommended medications in heart failure with reduced ejection fraction: data from the QUALIFY global survey. Eur J Heart Fail 18 (5):514-522

28. Savarese G, Carrero J-J, Pitt B, Anker SD, Rosano GMC, Dahlström U, Lund LH (2018) Factors associated with underuse of mineralocorticoid receptor antagonists in heart failure with reduced ejection fraction: an analysis of 11215 patients from the Swedish Heart Failure Registry. Eur J Heart Fail. doi:10.1002/ejhf.1182

29. Banka G, Heidenreich PA, Fonarow GC (2013) Incremental cost-effectiveness of guideline-directed medical therapies for heart failure. J Am Coll Cardiol 61:1440-1446

30. Rohde LE, Bertoldi EG, Goldraich L, Polanczyk CA (2013) Cost-effectiveness of heart failure therapies. Nat Rev Cardiol 10:338-354

31. Bapoje SR, Bahia A, Hokanson JE, Peterson PN, Heidenreich PA, Lindenfeld J, Allen LA, Masoudi FA (2013) Effects of mineralocorticoid receptor antagonists on the risk of sudden cardiac death in patients with left ventricular systolic dysfunction: A metaanalysis of randomized controlled trials. Circ Heart Fail 6:166-173

32. Rossello X, Ariti C, Pocock SJ, Ferreira JP, Girerd N, McMurray JJV, van Veldhuisen DJ, Pitt B, Zannad F (2018) Impact of mineralocorticoid receptor antagonists on the risk 
of sudden cardiac death in patients with heart failure and left ventricular systolic dysfunction: an individual patient-level meta-analysis of three randomized-controlled trials. Clin Res Cardiol:doi: 10.1007/s00392-00018-01378-00390. [Epub ahead of print]

33. Böhm M, Borer J, Ford I, Gonzalez-Juanatey JR, Komajda M, Lopez-Sendon J, Reil J-C, Swedberg K, Tavazzi L (2013) Heart rate at baseline influences the effect of ivabradine on cardiovascular outcomes in chronic heart failure: analysis from the SHIFT study. Clin Res Cardiol 102:11-22 
Page 18 of 24

\section{Legend to Figures}

\section{Figure 1}

Kaplan-Meier plots of major cardiovascular outcomes according to heart rate.

\section{Figure 2}

Adjusted event rates and 95\% CI by baseline heart rate categories on major cardiovascular outcomes.

\section{Figure 3}

Adjusted hazard ratio (eplerenone versus placebo) for all patients and by baseline heart rate categories for the primary endpoint, its components and all cause death. 
Page 19 of 24

Table 1. Baseline patient characteristics in the EMPHASIS-HF study according to baseline heart rate categories.

\begin{tabular}{|c|c|c|c|c|c|c|c|c|c|}
\hline \multirow[b]{3}{*}{ Eplerenone, $\mathbf{N}(\%)$} & \multicolumn{8}{|c|}{ Heart Rate } & \multirow{3}{*}{$\begin{array}{r}\text { P-value }^{1} \\
0.58\end{array}$} \\
\hline & \multicolumn{2}{|c|}{$\begin{array}{l}<60 \mathrm{bpm} \\
(\mathrm{N}=423)\end{array}$} & \multicolumn{2}{|c|}{$\begin{array}{c}\text { 60-69 bpm } \\
(\mathrm{N}=792)\end{array}$} & \multicolumn{2}{|c|}{$\begin{array}{c}70-79 \text { bpm } \\
(\mathrm{N}=697)\end{array}$} & \multicolumn{2}{|c|}{$\begin{array}{c}80+\text { bpm } \\
(\mathrm{N}=824)\end{array}$} & \\
\hline & 197 & (46.6) & 401 & (50.6) & 360 & (51.6) & 405 & $(49.2)$ & \\
\hline Age-years & 69.3 & $(7.5)$ & 68.8 & $(7.6)$ & 68.9 & (7.9) & 68.0 & $(7.5)$ & 0.006 \\
\hline Male, N(\%) & 344 & $(81.3)$ & 616 & (77.8) & 533 & (76.5) & 633 & $(76.8)$ & 0.10 \\
\hline Smoking, N(\%) & & & & & & & & & $<0.001$ \\
\hline Never & 173 & (40.9) & 334 & $(42.2)$ & 324 & (46.5) & 391 & $(47.5)$ & \\
\hline Current & 38 & $(9.0)$ & 83 & $(10.5)$ & 74 & $(10.6)$ & 98 & $(11.9)$ & \\
\hline Ex & 212 & $(50.1)$ & 375 & (47.3) & 299 & (42.9) & 335 & $(40.7)$ & \\
\hline Ethnicity, N(\%) & & & & & & & & & $<0.001$ \\
\hline White & 373 & $(88.2)$ & 696 & (87.9) & 575 & (82.5) & 623 & $(75.6)$ & \\
\hline Black & 5 & $(1.2)$ & 21 & $(2.7)$ & 24 & $(3.4)$ & 17 & $(2.1)$ & \\
\hline Asian & 30 & (7.1) & 53 & (6.7) & 72 & (10.3) & 161 & $(19.5)$ & \\
\hline Other & 15 & (3.5) & 22 & $(2.8)$ & 26 & (3.7) & 23 & $(2.8)$ & \\
\hline SBP-mmHg & 125.8 & (17.3) & 124.4 & (16.3) & 123.9 & (16.6) & 123.2 & (17.4) & 0.009 \\
\hline DBP-mmHg & 73.4 & $(10.5)$ & 73.6 & (9.8) & 74.8 & (10.1) & 76.1 & $(10.4)$ & $<0.001$ \\
\hline LVEF-\% & 26.6 & $(4.2)$ & 26.1 & (4.7) & 26.2 & $(4.7)$ & 25.8 & $(4.7)$ & 0.02 \\
\hline$B M I-k g / m^{2}$ & 27.6 & $(4.7)$ & 27.4 & (4.4) & 27.6 & (4.9) & 27.6 & (5.4) & 0.81 \\
\hline Principal cause of heart failure, $N(\%)$ & & & & & & & & & $<0.001$ \\
\hline Ischaemic & 309 & $(73.0)$ & 578 & $(73.0)$ & 469 & (67.3) & 530 & $(64.3)$ & \\
\hline Non-Ischaemic & 113 & $(26.7)$ & 214 & $(27.0)$ & 227 & (32.6) & 292 & $(35.4)$ & \\
\hline Unknown & 1 & $(0.2)$ & 0 & $(0.0)$ & 1 & $(0.1)$ & 2 & $(0.2)$ & \\
\hline Duration of HF-years & 4.9 & $(5.6)$ & 5.3 & (6.1) & 4.7 & (5.7) & 4.0 & (5.4) & $<0.001$ \\
\hline \multicolumn{10}{|l|}{ Medical History, N(\%) } \\
\hline Hospitalisation for heart failure & 190 & (44.9) & 439 & $(55.4)$ & 354 & $(50.8)$ & 456 & $(55.3)$ & 0.02 \\
\hline Hypertension & 289 & $(68.3)$ & 540 & $(68.2)$ & 455 & (65.3) & 535 & (64.9) & 0.11 \\
\hline
\end{tabular}




\begin{tabular}{|c|c|c|c|c|c|c|c|c|c|}
\hline Angina & 205 & $(48.5)$ & 393 & $(49.6)$ & 300 & $(43.0)$ & 291 & (35.3) & $<0.001$ \\
\hline Previous MI & 246 & $(58.2)$ & 450 & $(56.8)$ & 340 & $(48.8)$ & 345 & (41.9) & $<0.001$ \\
\hline $\mathrm{PCl}$ & 113 & $(26.7)$ & 195 & $(24.6)$ & 140 & $(20.1)$ & 148 & $(18.0)$ & $<0.001$ \\
\hline CABG & 84 & (19.9) & 185 & $(23.4)$ & 122 & $(17.5)$ & 125 & $(15.2)$ & $<0.001$ \\
\hline Atrial fibrillation or flutter & 101 & (23.9) & 201 & (25.4) & 210 & (30.1) & 332 & $(40.3)$ & $<0.001$ \\
\hline Any Pacemaker/CRT pacing & 31 & $(7.3)$ & 149 & $(18.8)$ & 129 & $(18.5)$ & 91 & (11.1) & 0.97 \\
\hline Left Bundle Branch Block & 101 & $(26.4)$ & 169 & $(27.0)$ & 158 & $(28.7)$ & 180 & (25.1) & 0.65 \\
\hline Right Bundle Branch Block & 27 & (7.0) & 45 & $(7.2)$ & 45 & $(8.2)$ & 51 & (7.1) & 0.89 \\
\hline Diabetes & 99 & $(23.4)$ & 231 & $(29.2)$ & 222 & (31.9) & 307 & (37.3) & $<0.001$ \\
\hline Stroke & 54 & $(12.8)$ & 75 & $(9.5)$ & 59 & $(8.5)$ & 74 & (9.0) & 0.06 \\
\hline ICD & 59 & (13.9) & 139 & $(17.6)$ & 94 & $(13.5)$ & 70 & (8.5) & $<0.001$ \\
\hline moglobin-g/dl & 13.7 & $(1.5)$ & 13.9 & $(1.5)$ & 13.8 & $(1.6)$ & 13.8 & (1.7) & 0.90 \\
\hline atinine-mg/dl & 1.2 & $(0.3)$ & 1.1 & $(0.3)$ & 1.1 & $(0.3)$ & 1.1 & $(0.3)$ & 0.02 \\
\hline $\mathrm{R}-\mathrm{ml} / \mathrm{min} / 1.73 \mathrm{~m}^{2}$ & 69.7 & $(20.5)$ & 70.9 & $(21.8)$ & 70.5 & $(22.9)$ & 71.5 & (21.6) & 0.25 \\
\hline eGFR<60-N.(\%) & 146 & (34.7) & 265 & (33.6) & 247 & $(35.5)$ & 248 & $(30.2)$ & 0.13 \\
\hline assium-mmol/l & 4.4 & $(0.4)$ & 4.3 & $(0.4)$ & 4.3 & $(0.4)$ & 4.3 & $(0.5)$ & 0.006 \\
\hline \multicolumn{10}{|c|}{ lication at randomisation visit, $\mathrm{N}(\%)$} \\
\hline Diuretic & 344 & $(81.3)$ & 649 & (81.9) & 576 & $(82.6)$ & 732 & $(88.8)$ & $<0.001$ \\
\hline ACE inhibitor & 323 & (76.4) & 610 & (77.0) & 543 & (77.9) & 626 & (76.0) & 0.84 \\
\hline ARB & 82 & (19.4) & 150 & (18.9) & 136 & (19.5) & 152 & (18.4) & 0.74 \\
\hline ACE and/or ARB & 393 & (92.9) & 732 & (92.4) & 652 & (93.5) & 755 & (91.6) & 0.51 \\
\hline Beta-blocker & 383 & (90.5) & 706 & (89.1) & 604 & (86.7) & 659 & $(80.0)$ & $<0.001$ \\
\hline Calcium Channel Blocker & 49 & $(11.6)$ & 82 & $(10.4)$ & 72 & $(10.3)$ & 73 & (8.9) & 0.14 \\
\hline Antiarrhythmic drug & 77 & (18.2) & 123 & (15.5) & 85 & $(12.2)$ & 97 & (11.8) & $<0.001$ \\
\hline Antithrombotic drug & 378 & (89.4) & 703 & (88.8) & 608 & $(87.2)$ & 703 & $(85.3)$ & 0.02 \\
\hline Digitalis glycosides & 73 & (17.3) & 154 & (19.4) & 197 & $(28.3)$ & 310 & (37.6) & $<0.001$ \\
\hline Lipid-lowering agent & 297 & $(70.2)$ & 517 & $(65.3)$ & 418 & $(60.0)$ & 457 & (55.5) & $<0.001$ \\
\hline
\end{tabular}

Numbers are mean (SD) unless otherwise specified; ${ }^{1} p$-value from test for trend 
Table 2: Number of events, event rate and hazard ratios by baseline heart rate categories for the primary endpoint, its component events and all cause death.

\begin{tabular}{|c|c|c|c|c|c|c|c|c|c|}
\hline Study Endpoint & N. & Events & $\left(\right.$ Rate $\left.^{1}\right)$ & HR & (95\% Cl) & P-value ${ }^{2}$ & Adj $H^{3}$ & $(95 \% \mathrm{Cl})$ & p-value ${ }^{2}$ \\
\hline \multicolumn{10}{|c|}{ Primary Endpoint } \\
\hline$<60$ & 423 & 96 & (11.4) & 1.09 & $(0.85,1.41)$ & & 1.15 & $(0.89,1.49)$ & \\
\hline $60-69$ & 792 & 162 & $(10.5)$ & \multicolumn{2}{|c|}{ Reference } & \multicolumn{4}{|c|}{ Reference } \\
\hline $70-79$ & 697 & 163 & $(12.0)$ & 1.15 & $(0.93,1.43)$ & & 1.16 & $(0.93,1.44)$ & \\
\hline $80+$ & 824 & 258 & $(17.2)$ & 1.64 & $(1.35,1.99)$ & $<0.001$ & 1.61 & $(1.31,1.99)$ & $<0.001$ \\
\hline \multicolumn{10}{|c|}{ Cardiovascular Death } \\
\hline$<60$ & 423 & 56 & $(6.2)$ & 1.16 & $(0.83,1.61)$ & & 1.16 & $(0.82,1.63)$ & \\
\hline $60-69$ & 792 & 90 & (5.4) & \multicolumn{2}{|c|}{ Reference } & \multicolumn{4}{|c|}{ Reference } \\
\hline $70-79$ & 697 & 94 & (6.4) & 1.18 & $(0.88,1.58)$ & & 1.15 & $(0.86,1.55)$ & \\
\hline $80+$ & 824 & 152 & (9.0) & 1.66 & $(1.28,2.16)$ & $<0.001$ & 1.57 & $(1.18,2.08)$ & 0.009 \\
\hline \multicolumn{10}{|c|}{ Hospitalization for Heart Failure } \\
\hline$<60$ & 423 & 59 & (7.0) & 0.93 & $(0.68,1.27)$ & & 1.04 & $(0.75,1.43)$ & \\
\hline $60-69$ & 792 & 117 & (7.5) & \multicolumn{2}{|c|}{ Reference } & \multicolumn{4}{|c|}{ Reference } \\
\hline $70-79$ & 697 & 110 & (8.1) & 1.08 & $(0.83,1.40)$ & & 1.07 & $(0.82,1.39)$ & \\
\hline $80+$ & 824 & 177 & $(11.8)$ & 1.55 & $(1.23,1.96)$ & $<0.001$ & 1.50 & $(1.16,1.93)$ & 0.006 \\
\hline \multicolumn{10}{|c|}{ All Cause Mortality } \\
\hline$<60$ & 423 & 63 & (7.0) & 1.05 & $(0.77,1.43)$ & & 1.06 & $(0.77,1.46)$ & \\
\hline $60-69$ & 792 & 111 & (6.7) & \multicolumn{2}{|c|}{ Reference } & \multicolumn{4}{|c|}{ Reference } \\
\hline $70-79$ & 697 & 107 & $(7.2)$ & 1.09 & $(0.83,1.42)$ & & 1.08 & $(0.82,1.42)$ & \\
\hline $80+$ & 824 & 176 & (10.4) & 1.56 & $(1.23,1.97)$ & $<0.001$ & 1.53 & $(1.18,1.98)$ & 0.003 \\
\hline
\end{tabular}

${ }^{1}$ Rate per 100 patient years; ${ }^{2} \mathrm{p}$-value from test for trend; ${ }^{3} \mathrm{HR}$ was adjusted for randomized treatment, age, sex, race, SBP, BMI, LVEF, serum creatinine, cause of $\mathrm{HF}$, duration of $\mathrm{HF}, \mathrm{DM}, \mathrm{AF}$, hypertension, prior hospitalization for HF, stroke, ICD/CRT, ACE inhibitors/ARBs, beta-blocker, CCB, digoxin, antiarrhythmic drugs. 
Figure 1. Kaplan-Meier plots of major cardiovascular outcomes according to heart rate.

A
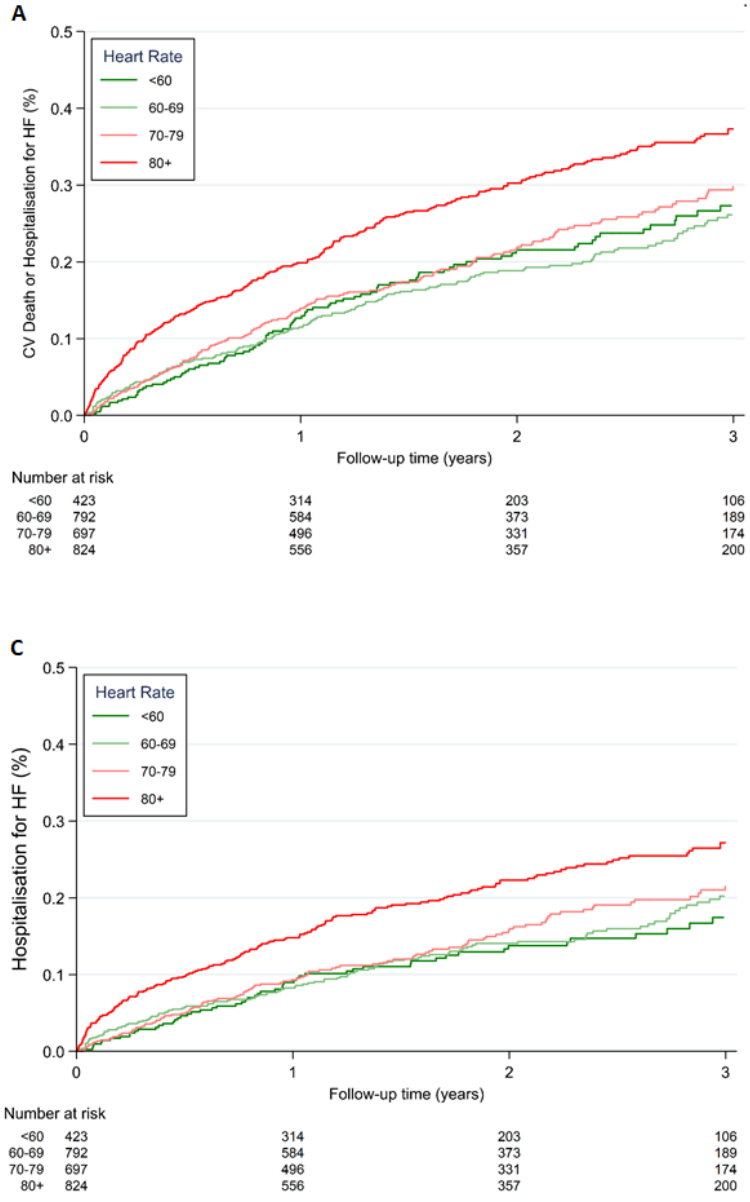

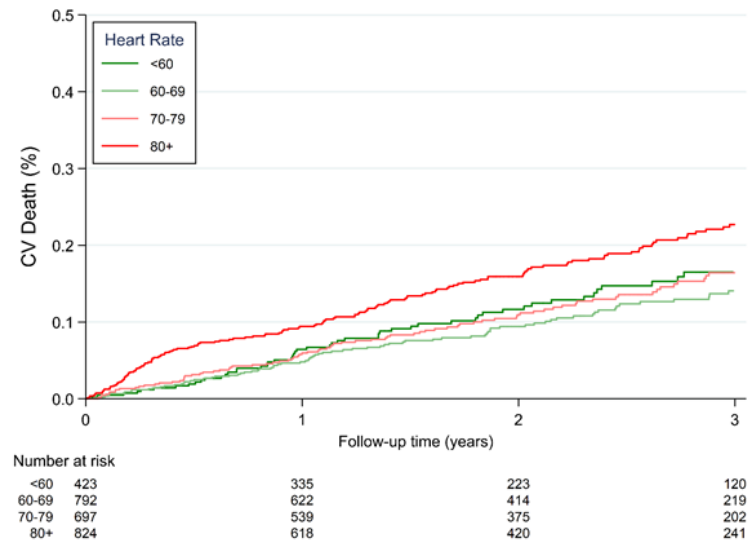

D

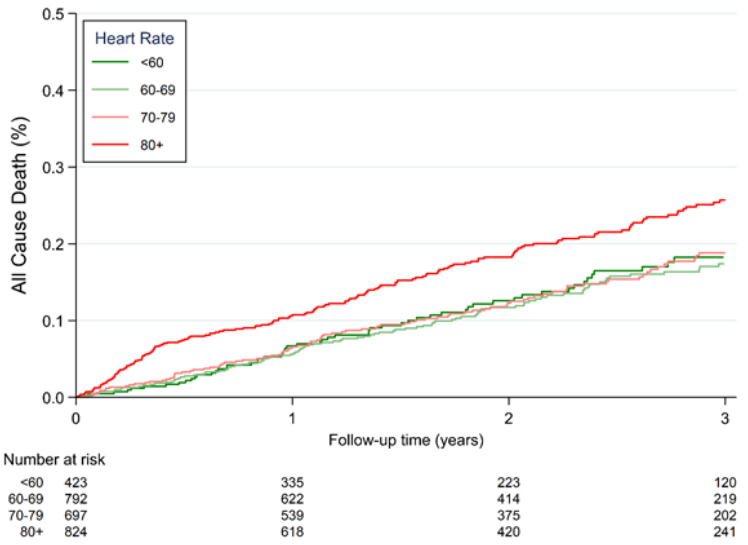


Figure 2. Adjusted event rates and $95 \% \mathrm{Cl}$ by baseline heart rate categories on major cardiovascular outcomes.
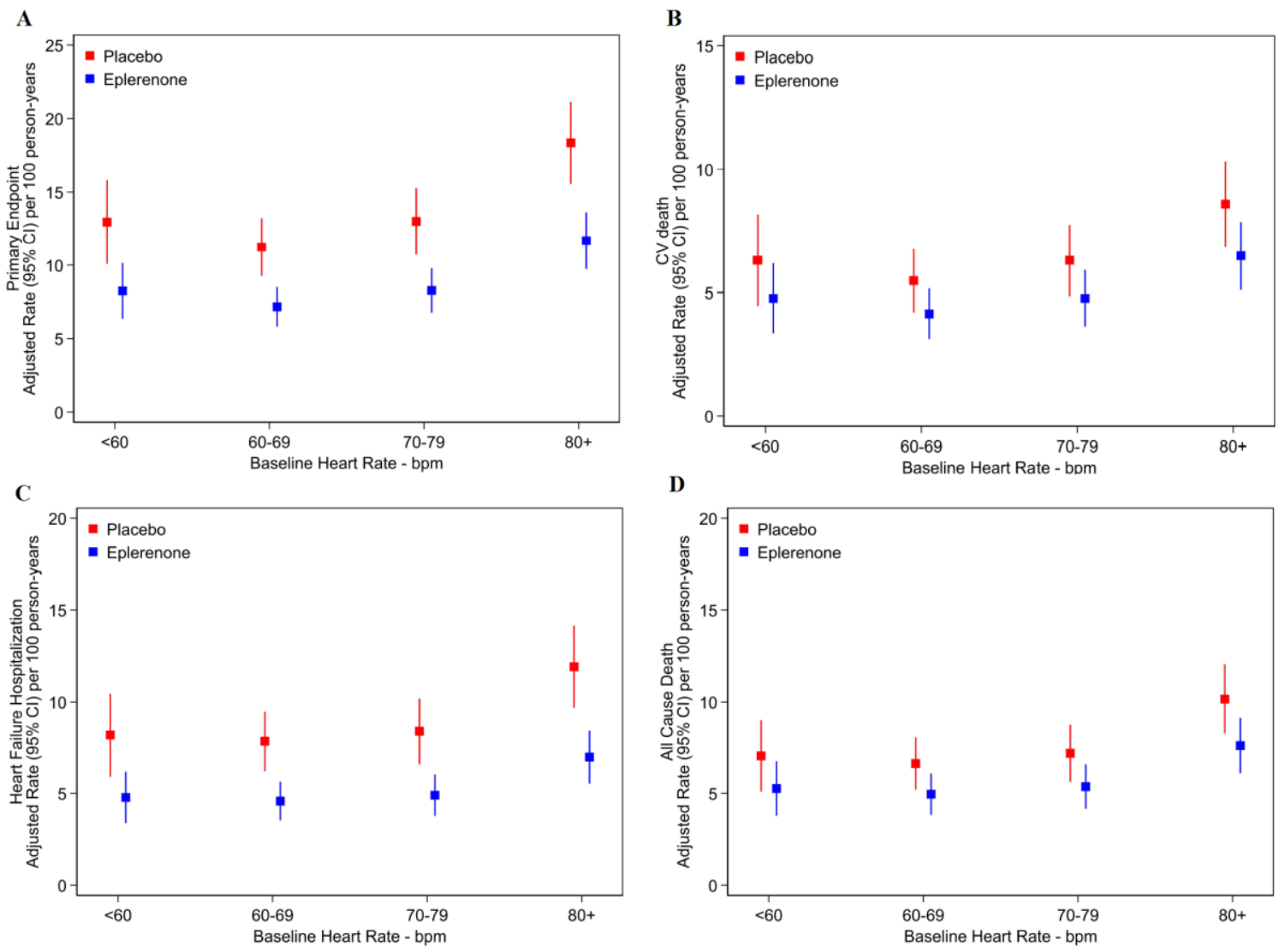

Note: Rates are estimated from a Poisson model and adjusted for: age, sex, race, SBP, BMI, LVEF, serum creatinine, cause of HF, duration of HF, DM, AF, hypertension, prior hospitalization for HF, stroke, ICD/CRT, ACE inhibitors/ARBs, beta-blocker, beta-blocker dose, CCB, digoxin, antiarrhythmic drugs. 
Figure 3. Adjusted hazard ratio (eplerenone versus placebo) for all patients and by baseline heart rate categories on major cardiovascular outcomes.

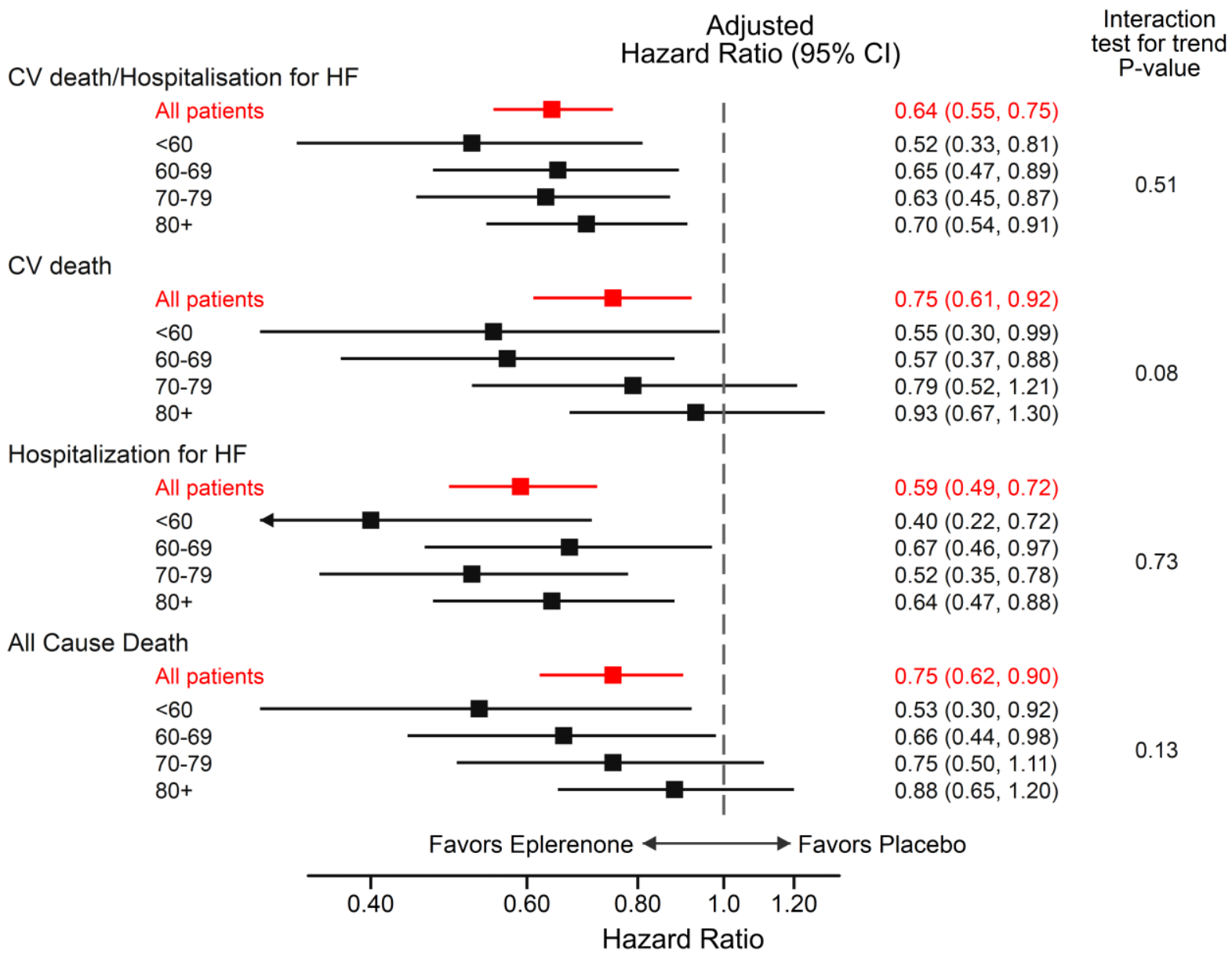

Note: Hazard ratio is adjusted for: age, sex, race, SBP, BMI, LVEF, serum creatinine, cause of HF, duration of HF, DM, AF, hypertension, prior hospitalization for HF, stroke, ICD/CRT, ACE inhibitors/ARBs, beta-blocker, beta-blocker dose, CCB, digoxin, antiarrhythmic drugs. 